\title{
ANALYSIS OF LEAF TOLERANCE TO MIDVEIN DAMAGE BY A SIMPLE MIDVEIN CUT-OFF TRIAL
}

\author{
W. L. Fu ${ }^{1,2,3}$, D. Y. $\mathrm{Li}^{1}$, Y. Cao ${ }^{1,3^{*}}$ and W. $\mathrm{Li}^{1,3}$ \\ ${ }^{1}$ Key Laboratory of Aquatic Botany and Watershed Ecology, Wuhan Botanical Garden, Chinese Academy of Sciences, \\ Wuhan 430074, China; ${ }^{2}$ University of Chinese Academy of Sciences, Beijing 100049, China \\ ${ }^{3}$ Hubei Key Laboratory of Wetland Evolution \& Ecological Restoration, Wuhan Botanical Garden, Chinese Academy of \\ Sciences, Wuhan 430074, China \\ Corresponding author's Email: caoyu@wbgcas.cn
}

\begin{abstract}
Venation type is an important trait for terrestrial plant leaves. Especially the midvein plays a crucial role in water and nutrient transportation and correlates with leaf tolerance to physical damage. In our study, we explored the leaf tolerance to midvein damages in 95 terrestrial species by a simple midvein cut-off trial. Within three months, no detectable changes of leaf intactness were found for over two-thirds of the selected species. In two species, Acer rubrum and Hylotelephium erythrostictum, over $10 \%$ of the leaf area was damaged by the end of the experiment. The diameter of the midvein and the leaf length showed a significantly positive correlation with the ratio of lamina damaged area to the total area (RLD), but the correlation became insignificant after including the phylogenetic relationships. The RLD varied considerably within each venation type (netted or parallel) while showed no significant difference and did not differ significantly between the two venation types; however, the RLD tended to be higher in herbaceous plants than in shrubs and trees. Our results indicated that the leaf tolerance to physical damages on the midvein of terrestrial plants was a trait somehow independent of phylogenetic relationships.
\end{abstract}

Keywords terrestrial plants; Acer rubrum; Hylotelephium erythrostictum; midvein damage; leaf tolerance; venation type

https://doi.org/10.36899/JAPS.2021.3.0264

Published online November 09, 2020

\section{INTRODUCTION}

Leaf is an essential photosynthetic organ and crucial to carbon fixation. There are two extremes on the leaf economics spectrum: one featuring thin leaves with a short life span and a high photosynthesis rate, the other featuring thick leaves with a long lifespan, but a low photosynthesis rate (Wright et al., 2004).

Besides the variation in leaf economic traits in terrestrial plants, the leaf structure is also diversified, e.g. compound leaf versus a single leaf, and the vein type can be netted, parallel or radical. The leaf venation is a key factor for species taxonomy ( $\mathrm{Yu}$ and Chen, 1991) and is a core component of water and nutrient transportation (Zwieniecki et al., 2002). Furthermore, the leaf venation network plays a critical role in the leaf functional traits based on research on over 2000 species (Blonder et al., 2011), and the vein density is an essential characteristic of leaf venation. Additionally, the midvein, sometimes called the major vein, has demonstrated to affect the leaf functional traits (Sack et al. 2012; Sack and Scofoni. 2013). The vein scaling relationship describes that the thicker the midvein, the larger the expected leaf area (Sack et al., 2012).

The midvein serves as the backbone of the leaf venation network. Previous studies mainly focused on the role of the midvein in intact leaves (Wright et al., 2004;
Sack et al., 2012) however, in natural conditions, the leaves commonly suffer from physical damages. For example, the grazing of insects would induce significant alterations in the leaf structure, and these effects are related to leaf morphological traits (Edwards and Wratten. 1983; Brown and Lawton. 1991). The tolerance to midvein damages could be essential to leaf survival and photosynthesis. For instance, Harayama (Harayama et al. 2019) detected that the blockage of the major vein induced a rapid decline in stomatal conductance in the vine species Pueraria lobata. Here, we aim to find the responses of terrestrial plant leaves to physical midvein damage (simulated by a midvein cut-off) and to investigate the potential correlation between plant traits (such as leaf morphology and plant life forms) and leaf tolerance to external damages based on the research on over 90 terrestrial species with the hypothesis that the midvein damage would induce significantly adverse effects on leaf growth and intactness.

\section{MATERIALS AND METHODS}

Initially, 104 single leaf type species were treated in Wuhan Botanical Garden in September, 2018. A simple method was used to simulate the leaf damage: a cut-off of the midvein at $1 / 4$ of the total length near the leaf base was performed with a needle (shown in Figure 
1) (Harayama et al. 2019). The cut was not sealed with cyanoacrylate as described in previous studies (Harayama et al., 2019; Nardini and Salleo, 2003) in order to mimic physical damage in natural circumstances compared to a midvein blockage.. The damaged leaves were tagged with a plastic label. Five healthy and mature leaves of each species were randomly chosen to serve as replicates, other untreated leaves were used as controls. A weekly observation of the leaf growth was conducted. After three months, 95 out of 104 species were selected for further analysis after discarding species affected by human disturbance (e.g. the removal of tags or the whole leaf). Those species consisted of 20 herbs, 39 shrubs and 36 trees. The plants could be divided according to the leaf venation type: 78 species had netted veins and 17 species had parallel veins. General information on the species is shown in Table 1.
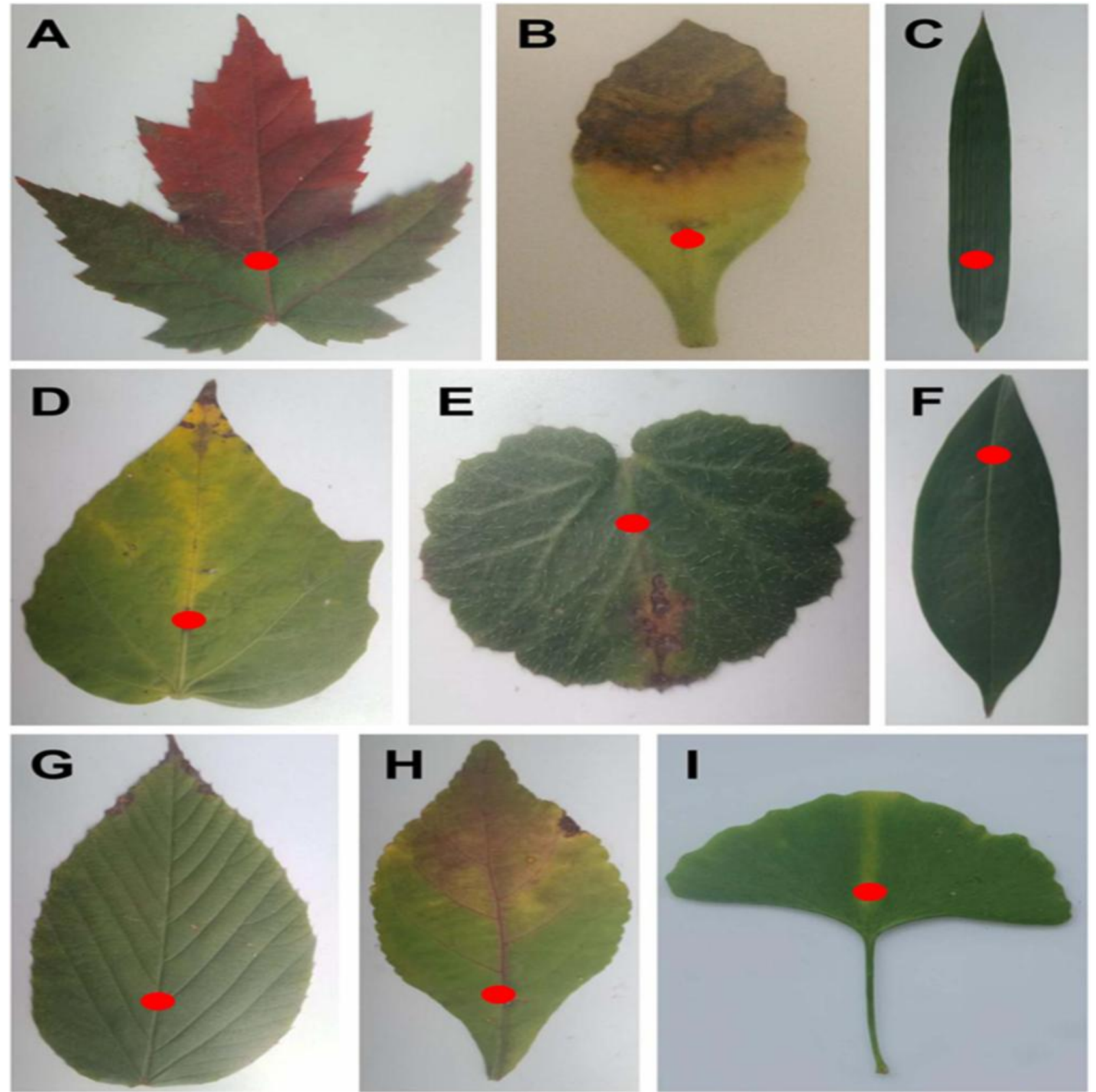

Figure 1 An example of leaves showing insignificant and serious leaf damage symptoms after the midvein cut-off.

(A) Acer rubrum, (B) Hylotelephium erythrostictum, (C) Bambusa chungii, (D) Hibiscus moscheutos, (E) Saxifraga stolonifera, (F) Illicium dunnianum, (G) Corylopsis multiflora, (H) Callicarpa bodinieri, (I) Ginkgo biloba. The cut-off point is marked with a red dot. 
Table 1. The basic information of the chosen 95 species based on APG III classification system.

\begin{tabular}{|c|c|c|c|}
\hline Species & Family & Life form & Venation type \\
\hline Acer rubrum & Aceraceae & tree & netted \\
\hline Actinodaphne forrestii & Lauraceae & tree & netted \\
\hline Annona squamosa & Annonaceae & tree & netted \\
\hline Arundo donax & Poaceae & herb & parallel \\
\hline Aspidistra elatior & Asparagaceae & herb & parallel \\
\hline Bambusa chungii & Poaceae & herb & parallel \\
\hline Buxus henryi & Buxaceae & shrub & netted \\
\hline Callicarpa cathayana & Lamiaceae & shrub & netted \\
\hline Camellia cuspidate & Theaceae & shrub & netted \\
\hline Camellia grijsii & Theaceae & shrub & netted \\
\hline Camellia japonica & Theaceae & shrub & netted \\
\hline Camellia oleifera & Theaceae & shrub & netted \\
\hline Camellia sasanqua & Theaceae & tree & netted \\
\hline Canna indica & Cannaceae & herb & netted \\
\hline Celastrus hindsii & Celastraceae & shrub & netted \\
\hline Celtis julianae & Cannabaceae & tree & netted \\
\hline Celtis sinensis & Cannabaceae & tree & netted \\
\hline Chimonanthus praecox & Calycanthaceae & shrub & netted \\
\hline Cinnamomum camphora & Lauraceae & tree & netted \\
\hline Cinnamomum burmanii & Lauraceae & tree & netted \\
\hline Corylopsis sinensis & Hamamelidaceae & shrub & netted \\
\hline Disporopsis fuscopicta & Asparagaceae & herb & netted \\
\hline Distylium buxifolium & Hamamelidaceae & shrub & netted \\
\hline Distylium chinense & Hamamelidaceae & shrub & netted \\
\hline Distylium racemosum & Hamamelidaceae & shrub & netted \\
\hline Elaeagnus lanceolate & Elaeagnaceae & shrub & netted \\
\hline Elaeagnus pungens & Elaeagnaceae & shrub & netted \\
\hline Eriobotrya japonica & Rosaceae & tree & netted \\
\hline Euonymus alatus & Celastraceae & shrub & netted \\
\hline Euonymus fortune & Celastraceae & shrub & netted \\
\hline Fatsia japonica & Araliaceae & shrub & netted \\
\hline Ficus tikoua & Moraceae & shrub & netted \\
\hline Flueggea suffruticosa & Phyllanthaceae & shrub & netted \\
\hline Gardenia jasminoides & Rubiaceae & shrub & netted \\
\hline Gardenia jasminoides var. radicans & Rubiaceae & shrub & netted \\
\hline Hainania trichosperma & Malvaceae & shrub & parallel \\
\hline Hedera nepalensis var. sinensis & Araliaceae & shrub & netted \\
\hline Hibiscus moscheutos & Malvaceae & herb & netted \\
\hline Hosta ventricosa & Asparagaceae & herb & parallel \\
\hline Hydrangea macrophylla & Saxifragaceae & shrub & netted \\
\hline Hylotelephium erythrostictum & Crassulaceae & herb & netted \\
\hline Ilex cornuta & Aquifoliaceae & shrub & netted \\
\hline Ilex corunta var. fortune & Aquifoliaceae & shrub & netted \\
\hline Ilex integra & Aquifoliaceae & tree & netted \\
\hline Ilex latifolia & Aquifoliaceae & tree & netted \\
\hline Illicium dunnianum & Schisandraceae & shrub & netted \\
\hline Illicium henryi & Schisandraceae & shrub & netted \\
\hline Indocalamus tessellatus & Poaceae & herb & parallel \\
\hline Kolkwitzia amabilis & Caprifoliaceae & shrub & netted \\
\hline Lindera megaphylla & Lauraceae & tree & netted \\
\hline Liriodendron chinense & Magnoliaceae & tree & netted \\
\hline Liriope muscari & Asparagaceae & herb & parallel \\
\hline
\end{tabular}




\begin{tabular}{|c|c|c|c|}
\hline Litsea coreana var. sinensis & Lauraceae & tree & netted \\
\hline Machilus ichangensis & Lauraceae & tree & netted \\
\hline Machilus salicina & Lauraceae & tree & netted \\
\hline Machilus velutina & Lauraceae & tree & netted \\
\hline Magnolia biondii & Magnoliaceae & tree & netted \\
\hline Manglietia patungensis & Magnoliaceae & tree & netted \\
\hline Manglietia szechuanica & Magnoliaceae & tree & netted \\
\hline Manglietia yuyuanensis & Magnoliaceae & tree & netted \\
\hline Melliodendron xylocarpum & Styracaceae & tree & netted \\
\hline Michelia figo & Magnoliaceae & shrub & netted \\
\hline Michelia martinii & Magnoliaceae & tree & netted \\
\hline Mussaenda esquirolii & Rubiaceae & shrub & netted \\
\hline Myrica rubra & Myricaceae & tree & netted \\
\hline Nageia nagi & Podocarpaceae & tree & parallel \\
\hline Osmanthus fragrans & Oleaceae & tree & netted \\
\hline Osmanthus yunnanensis & Oleaceae & shrub & netted \\
\hline Parakmeria omeiensis & Magnoliaceae & tree & netted \\
\hline Phoebe bournei & Lauraceae & tree & netted \\
\hline Phoebe faberi & Lauraceae & tree & netted \\
\hline Phoebe nanmu & Lauraceae & tree & netted \\
\hline Photinia davidsoniae & Rosaceae & tree & netted \\
\hline Phyllostachys bambusoides & Poaceae & herb & parallel \\
\hline Phyllostachys dulcis & Poaceae & herb & parallel \\
\hline Phyllostachys aureosulcata cv. 'Spectabilis' & Poaceae & herb & parallel \\
\hline Pittosporum tobira & Pittosporaceae & shrub & netted \\
\hline Pleioblastus oleosus & Poaceae & herb & parallel \\
\hline Pollia japonica & Commelinaceae & herb & parallel \\
\hline Reineckea carnea & Asparagaceae & herb & parallel \\
\hline Rubus parvifolius & Rosaceae & shrub & netted \\
\hline Ruellia brittoniana & Acanthaceae & herb & netted \\
\hline Sapium sebiferum & Euphorbiaceae & tree & netted \\
\hline Setaria palmifolia & Poaceae & herb & parallel \\
\hline Shibataea chinensis & Poaceae & herb & parallel \\
\hline Sinojackia xylocarpa & Styracaceae & tree & netted \\
\hline Symplocos tetragona & Symplocaceae & tree & netted \\
\hline Ternstroemia gymnanthera & Theaceae & shrub & netted \\
\hline Trachelospermum jasminoides & Apocynaceae & shrub & netted \\
\hline Ulmus parvifolia & Ulmaceae & tree & netted \\
\hline Viburnum brachybotryum & Adoxaceae & shrub & netted \\
\hline Viburnum odoratissimum & Adoxaceae & shrub & netted \\
\hline Viburnum rhytidophyllum & Adoxaceae & shrub & netted \\
\hline Zelkova schneideriana & Ulmaceae & tree & netted \\
\hline Zingiber officinale & Zingiberaceae & herb & parallel \\
\hline
\end{tabular}

A digital camera (Sony ILCE-6000, Tokyo, Japan) was used to capture the form of the leaves. The images were analyzed with SC-E software (Hangzhou Wanshen Detection Technology Co., Ltd., Hangzhou, China) to measure the length, width, perimeter and area of the lamina (excluding the petiole) of ten randomly chosen healthy and mature leaves of each species (Fang et al. 2015). The thickness of the leaf's edge and midvein was measured by a Vernier caliper, and the dry leaf weight was measured after being oven-dried at $80{ }^{\circ} \mathrm{C}$ for $24 \mathrm{~h}$. Five additional healthy and mature leaves were harvested per species and an electric body fluorescence microscopy imaging system (Nikon SMZ25, Tokyo, Japan) was used for further analysis of the leaf vein structure (Li. 2017). The leaf vein density of only 36 species was obtained by PhenoVein following the instructions of Bühler (Bühler et al., 2015). For the species that displayed almost no changes in leaf intactness at the end of the experiment, only one leaf was harvested. For the species that displayed significant leaf damage, two or more leaves were harvested. After harvest, the ratio of the damaged area (leaf damage ratio) was determined using the method mentioned above and by separately measuring the total and damaged area of 
the lamina. The ratio of lamina damaged area to the total area (RLD) was also calculated. The mean values were further used in the study.

Climatic data was collected from a local weather station from 26 September to 8 December 2018. The data are shown in Figure S1 in the appendix.

The phylogenetic relationship between the chosen species based on APG III classification system was obtained using the 'Phylomatic' function in the package 'brranching' in R 3.5.1, and the phylogeny tree from Zanne (Zanne et al. 2014) was used. The phylogenetic similarities between the leaf traits and the RLD of the assayed species were analyzed with the function 'multiPhylosignal' in the package 'picante'. The traits were considered phylogenetically conservative when the K-values were close to 1 or the p-values $<0.05$. The correlation between the RLD and indicators of the leaf morphology, such as plant life form or venation type, was analyzed with/without the phylogenetic data. When the phylogenetic data were included, the following formula was applied: model<-gls (damage_ratio indicators, correlation $=$ corBrownian(value $=1$,phy), data $=$ traits), based on the 'picante' package. The data were log-transformed to satisfy the assumption of the analysis.

\section{RESULTS}

For the 95 selected species, the lamina area ranged from 5.5 to $552.1 \mathrm{~cm}^{2}$, and the leaf midvein diameter ranged from 0.376 to $5.100 \mathrm{~mm}$ (Table 2). A total of 73 species showed negligible changes (less than $0.1 \%$ of the lamina area) in leaf intactness after the midvein cut-off. The leaf vein density ranged from 1.92 to $9.13 \mathrm{~mm} \mathrm{~mm}^{-2}$. The four species with an RLD over $5 \%$ at the end of the experiment are Hosta ventricosa (6.1\%), Hibiscus moscheutos (6.4\%), Acer rubrum (14.9\%), and Hylotelephium erythrostictum (17.4\%).

Leaf traits, including area, perimeter, length, width, dry weight, edge thickness, and midvein diameter, did not show significant phylogenetic signals $(\mathrm{K}<0.25$ and $\mathrm{p}>0.05)$. However, the RLD displayed significant phylogenetic signals ( $\mathrm{K}$ values $>0.3$ and $\mathrm{p}<0.01$ ) as shown in Figure 2.

Many plant species exhibited contrasting responses after cutting off the midveins as shown in Figure 1. Results showed lamina length and midvein diameter were significantly related to the RLD when the phylogenetic data were not included, while no leaf trait was significantly correlated when the phylogenetic data were included (Table 3).

Of the 36 species with their vein density determined, five species (Sinojackia xylocarpa, Melliodendron xylocarpum, Magnolia biondii, Euonymus alatus, and Celtis julianae) were found with detectable changes $(>0.1 \%$ lamina area) in leaf damage, and all had a leaf vein density $<5 \mathrm{~mm} \mathrm{~mm}^{-2}$.

The correlation analysis of leaf venation type and plant life form revealed an insignificant effect of leaf vein types (parallel and netted) on RLD, independent of the phylogenetic data $(\mathrm{F}<2.3, \mathrm{p}>0.05)$. Meanwhile, the RLD differed among the three plant life forms when the phylogenetic data were not included $(F=3.79, p<0.05)$ : the herbaceous plants had a higher RLD than the two other life forms (Figure 3). However, plant life forms no longer significantly affected the RLD when the phylogenetic data were included $(\mathrm{F}=1.42, \mathrm{p}>0.05)$.

Table 2 The values of leaf traits (morphology and venation type) and the ratio of lamina damaged area to the total area (RLD).

\begin{tabular}{ll}
\hline Indicators & Range (median) \\
\hline Lamina area $\left(\mathrm{cm}^{2}\right)$ & $5.5 \sim 552.1(114.6)$ \\
Lamina perimeter $(\mathrm{cm})$ & $12.9 \sim 386.8(81.0)$ \\
Lamina length $(\mathrm{cm})$ & $5.7 \sim 51.9(30.7)$ \\
Lamina width $(\mathrm{cm})$ & $1.2 \sim 34.6(11.4)$ \\
Leaf dry weight $(\mathrm{g})$ & $0.033 \sim 4.239(0.249)$ \\
Leaf edge thickness $(\mathrm{cm})$ & $0.097 \sim 0.706(0.258)$ \\
Leaf midvein diameter $(\mathrm{mm})$ & $0.38 \sim 5.10(0.90)$ \\
Leaf vein density $\left(\mathrm{mm} \mathrm{mm}^{-2}\right)$ & $1.92 \sim 9.13(4.97)$ \\
RLD $(\%)$ & $0 \sim 17(0)$ \\
\hline
\end{tabular}




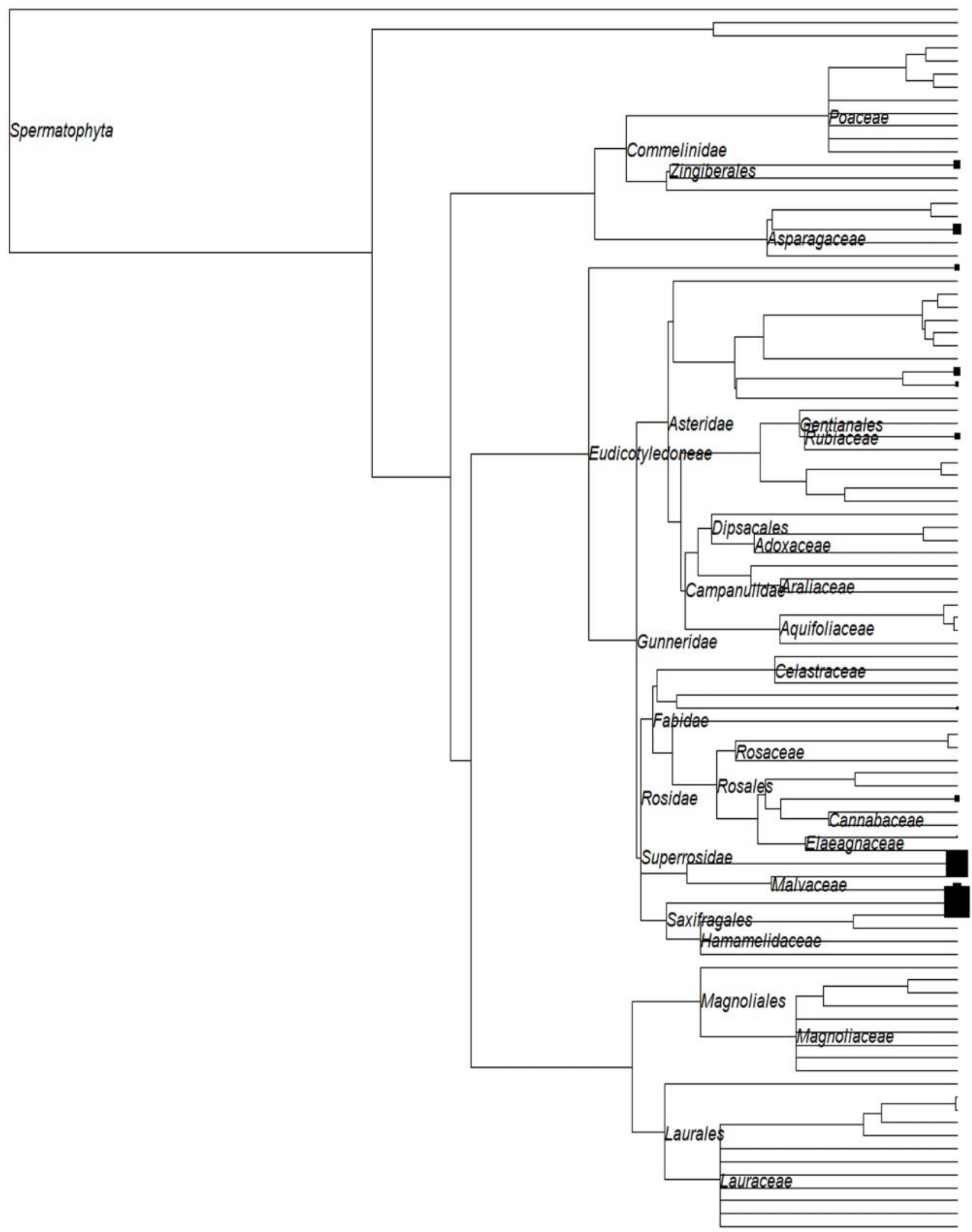

Figure 2. The phylogenetic signals of the ratio of lamina damaged area to the total area (RLD) among the selected species. 
Table 3 Summary of the correlation analysis between the ratio of lamina damaged area to total area (RLD), and leaf traits with or without the phylogenetic data.

\begin{tabular}{lcccc}
\hline & \multicolumn{2}{c}{ Not including phylogenetic relationship } & \multicolumn{2}{c}{ Including phylogenetic relationship } \\
\hline & F value & Sig. & F value & Sig. \\
\hline Lamina area & 0.57 & 0.45 & 0.31 & 0.58 \\
Lamina perimeter & 3.07 & 0.08 & 0.47 & 0.49 \\
Lamina length & 6.99 & $<0.01, * *$ & 1.55 & 0.21 \\
Lamina width & 0.66 & 0.42 & 0.21 & 0.65 \\
Leaf dry weight & 2.09 & 0.15 & 0.30 & 0.59 \\
Midvein diameter & 4.86 & $0.03, *$ & 2.45 & 0.12 \\
\hline
\end{tabular}

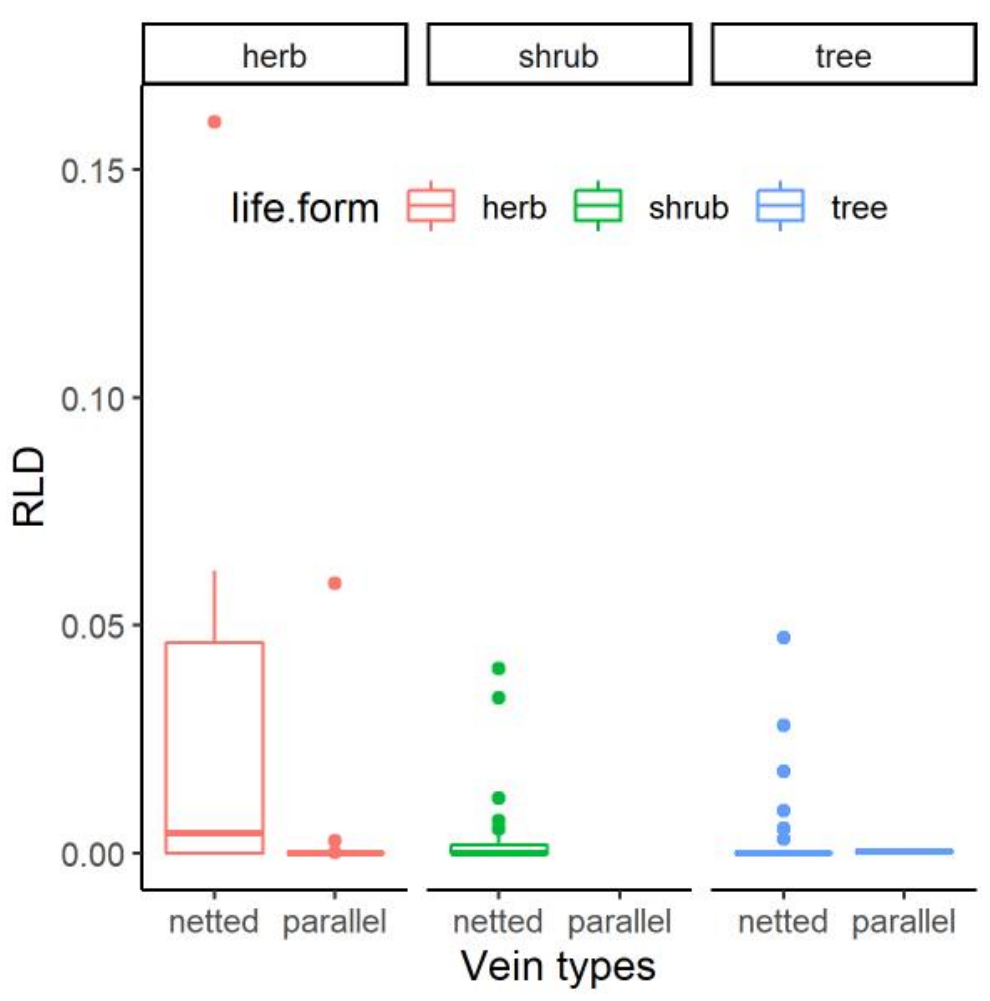

Figure 3 The ratio of lamina damaged area to the total area (RLD) between the three plant life forms and two venation types.

\section{DISCUSSION}

In contrast to our hypothesis, over two-thirds of the 95 selected species did not show significant leaf damages three months after the midvein cut-off, though there was a strong variation in the response of the remaining 22 species. Previous studies on the species Prunus laurocerasus revealed that the leaf water potential did not drop after the midvein cut-off, though a severe decrease of leaf hydraulic conductance indicated a physiological homeostatic maintenance (Nardini and Salleo, 2003). Furthermore, it was predicted that a tradeoff existed between vein architecture at a macroscopic scale and cell-to-cell pathway at a microscopic scale for water transportation based on a similar midvein cut experiment (Harayama et al. 2019). The leaf venation network is complex and consists of different sizes of areoles (Blonder et al. 2011), These small connected structures probably take over the function of nutrient and water transportation after the midvein cut-off.

The correlation between RLD and lamina length or leaf midvein diameter was significant when the phylogenetic data were not included in our study. The vein scaling relationship revealed that larger leaves require more physical supports from the midvein, and thus, the diameter of the midvein strongly and positively correlated with the leaf size (Sack et al. 2012). It is reasonable to assume more extent of leaf damage after midvein cut-off for larger leaves with thicker midveins, as was demonstrated in our study. Usually, the texture of the leaves was closely linked with leaf thickness, and our 
results suggested that the thicker succulent leaves would be more vulnerable to midvein damages. Meanwhile, a study on nine aquatic species found that the species with parallels veins were more tolerant to the midvein cut-off than the other two venation types (Pan et al. 2019). This could be resulted by the compensation of other parallel veins that were not damaged. In contrast, no significant differences were found between the species with parallel veins and netted veins in our study. The lack of a significant difference between venation types probably reflected a high species variation within each venation type due to a high species abundancy compared to Pan et al. (2019).

There are also other potentially important factors that play a role in affecting the response of leaf to midvein cutoff. Defoliation and evergreen also affect the physiological activity of leaves (Gaxiola and Armesto, 2015; Qin and Shangguan, 2019), which could strongly interact with the treatment of midvein damage. Wright et al. (2004) stated that the leaf life span is a key plant trait for leaf economics spectrum, and leaves with short lifespan would be expected to have lower construction cost and thus be prone to decay after damages. However, the leave lifespan is unfortunately not measured in this study.

In conclusion, we found that the variation of leaf tolerance to mechanical damages for different species was somehow independent of their phylogenetic relationship. It is also implied that herbaceous plants or leaves with low leaf vein density more seriously suffered after the midvein cut-off, which fits well with physical feature of leaf structure. As a shortcoming, the study was performed in a relatively short term and with no recoding of changes of physiological indicators; especially the latter, which should provide better understanding of the leaf tolerance to external damages.

Acknowledgements: We thank the assistance from B Wang and FH Deng for the sampling.

\section{REFERRENCES}

Blonder, B., C. Violle, L.P. Bentley, and B.J. Enquist (2011). Venation networks and the origin of the leaf economics spectrum. Ecol. Lett. 14: 91100.

Brown, V.K., and J.H. Lawton (1991). Herbivory and the evolution of leaf size and shape. Philos. Trans. R. Soc. London. Ser. B Biol. Sci. 333: 265-272.

Bühler, J., L. Rishmawi, D. Pflugfelder, G. Huber, H. Scharr, M. Hülskamp, M. Koornneef, U. Schurr, and S. Jahnke (2015). phenoVein - a tool for leaf vein segmentation and analysis. Plant Physiol. 169: 2359-2370.
Edwards, P.J., and S.D. Wratten (1983). Wound induced defences in plants and their consequences for patterns of insect grazing. Oecologia. 59: 88-93.

Fang, C., X. Hu, C. Sun, B. Duan, L. Xie, and P. Zhou (2015). Simultaneous determination of multi rice quality parameters using image analysis method. Food Anal. Methods 8: 70-78.

Gaxiola, A., and J.J. Armesto (2015). Understanding litter decomposition in semiarid ecosystems: linking leaf traits, UV exposure and rainfall variability. Front. Plant Sci. 140-140.

Harayama, H., M. Kitao, E. Agathokleous, and A. Ishida (2019). Effects of major vein blockage and aquaporin inhibition on leaf hydraulics and stomatal conductance. Proc. R. Soc. B 286: 20190799.

Li, F.F. (2017). Making leaf vein bookmark exploration of biology extracurricular practice course. B Biol. 52(4): 57-59 (in Chinese).

Nardini, A., and S. Salleo (2003). Effects of the experimental blockage of the major veins on hydraulics and gas exchange of Prunus laurocerasus L. leaves. J. Exp. Bot. 54: 12131219.

Pan, J.F., B Wang, D.Y. Li, Q. Feng, M.Y. Guo, L. Li, H.Y. Lu, D. She, Y.W. Yu, T.M. Zhao, and Y. Cao (2019). Effects of mechanical damage on leaf veins of nine aquatic plants. Plant Sci. J., 37: 230-239 (in Chinese).

Qin, J., and Z.P. Shangguan (2019). Effects of forest types on leaf functional traits and their interrelationships of Pinus massoniana coniferous and broad-leaved mixed forests in the subtropical mountain, Southeastern China. Ecol. Evol. 9(12): 6922-6932.

Sack, L., and C. Scoffoni (2013). Leaf venation: structure, function, development, evolution, ecology and applications in the past, present and future. New Phytol. 198: 983-1000.

Sack, L., C. Scoffoni, A.D. Mckown, K. Frole, M. Rawls, J.C. Havran, H. Tran, and T. Tran (2012). Developmentally based scaling of leaf venation architecture explains global ecological patterns. Nat. Commun. 3: 837.

Wright, I.J., P.B. Reich, M. Westoby, D.D. Ackerly, Z. Baruch, F. Bongers, J. Cavenderbares, T.Chapin, J.H.C. Cornelissen, M. Diemer, J. Flexas, E. Garnier, P.K. Groom, J. Gulias, K. Hikosaka, B.B. Lamont, T.D. Lee, W.G. Lee, C.H. Lusk, J.J. Midgley, M. Navas, U. Niinemets, J. Oleksyn, N. Osada, H. Poorter, P. Poot, L. D. Prior, V.I. Pyankov, C. Roumet, S.C. Thomas, M.G. Tjoelker, E.J. Veneklaas, and R.Villar (2004). The worldwide leaf economics spectrum. Nature. 428(6985): 821. 
Yu, C.H., and Z.L. Chen (1991). Leaf architecture of the woody dicotyledons from tropical and subtropical China.

Zanne, A.E., D.C. Tank, W.K. Cornwell, J.M. Eastman, S.A. Smith, R.G. Fitzjohn, D.J. Mcglinn, B.C. Omeara, A.T. Moles, P. B. Reich, D.L. Royer, D.E. Soltis, P. F. Stevens, M. Westoby, I. J. Wright, L.W. Aarssen, R.I. Bertin, A. Calaminus, R. Govaerts, F.A. Hemmings, M.R. Leishman, J. Oleksyn, P. S. Soltis, N.G. Swenson, L. Warman, and J.M. Beaulieu (2014). Three keys to the radiation of angiosperms into freezing environments. Nature. 506: 89-92.
Zwieniecki, M.A., P.J. Melcher, C.K. Boyce, L. Sack, and N.M. Holbrook (2002). Hydraulic architecture of leaf venation in Laurus nobilis L. Plant. Cell Environ. 25: 1445-1450.

Hourly climate data including air quality index (AQI), air temperature (Temp), relative moisture (RM) and precipitation (Prec): The air quality index was relatively low during the experiment (except for short-term high values near the end of the experiment). There were a few mildly rainy days during our experimental experiment, and the relatively moisture fluctuated. The air temperature gradually decreased and reached $<10{ }^{\circ} \mathrm{C}$ at the end of the experiment.

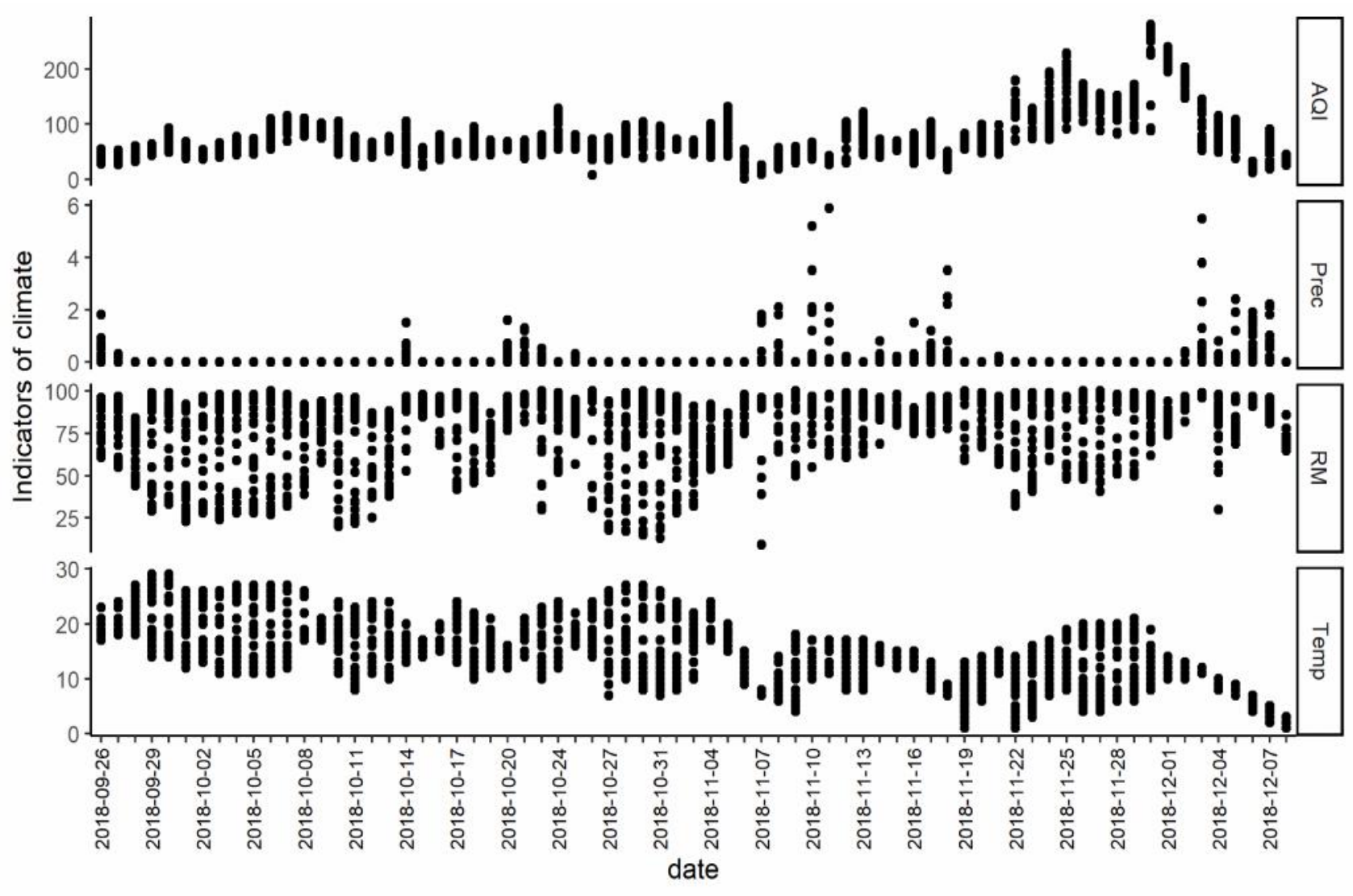

Figure S1 Hourly climate data including air quality index (AQI), air temperature (Temp, unit: $\left.{ }^{\circ} \mathrm{C}\right)$, relative moisture (RM) and precipitation (Prec, unit: $\mathrm{mm}$ ) from $26^{\text {th }}$ September to $8^{\text {th }}$ December, 2018. 